\title{
Quorum sensing communication between bacteria and human cells: signals, targets, and functions
}

Angelika Holm and Elena Vikström*

Division of Medical Microbiology, Department of Clinical and Experimental Medicine, Faculty of Health Sciences, Linköping University, Linköping, Sweden

\section{Edited by:}

Adam Schikora, Justus Liebig

University Giessen, Germany

\section{Reviewed by:}

Leighton Pritchard, James Hutton

Institute, UK

Vittorio Venturi, International Centre

for Genetic Engineering and

Biotechnology, Italy

\section{*Correspondence:}

Elena Vikström, Division of Medical Microbiology, Department of Clinical and Experimental Medicine, Faculty of Health Sciences, Linköping University, Linköping SE-58185, Sweden e-mail: elena.vikstrom@liu.se

\begin{abstract}
Both direct and long-range interactions between pathogenic Pseudomonas aeruginosa bacteria and their eukaryotic hosts are important in the outcome of infections. For cellto-cell communication, these bacteria employ the quorum sensing (OS) system to pass on information of the density of the bacterial population and collectively switch on virulence factor production, biofilm formation, and resistance development. Thus, QS allows bacteria to behave as a community to perform tasks which would be impossible for individual cells, e.g., to overcome defense and immune systems and establish infections in higher organisms. This review highlights these aspects of $Q S$ and our own recent research on how $P$. aeruginosa communicates with human cells using the small QS signal molecules $\mathrm{N}$-acyl homoserine lactones (AHL). We focus on how this conversation changes the behavior and function of neutrophils, macrophages, and epithelial cells and on how the signaling machinery in human cells responsible for the recognition of AHL. Understanding the bacteria-host relationships at both cellular and molecular levels is essential for the identification of new targets and for the development of novel strategies to fight bacterial infections in the future.
\end{abstract}

Keywords: bacteria-host cell interaction, quorum sensing, Pseudomonas aeruginosa, $\boldsymbol{N}$-acyl homoserine lactones, epithelial cells, innate immune cells, neutrophils, macrophages

\section{INTRODUCTION}

Pseudomonas aeruginosa is an environmentally highly adaptable Gram-negative bacterium that infects different host species, including higher plants, invertebrates, and vertebrates. In humans, it elicits acute and chronic infections, typically in critically ill patients having compromised epithelial barriers and immune system or the genetic disorder cystic fibrosis. The outcome of infections and establishment of disease depends on both host defence and bacterial capacities. The latter include its autonomic efficiency to grow, divide, and adapt to the environment, and the ability to sense, and communicate with their neighbors in the population to accomplish cooperative activities, e.g., biofilm formation and production of virulence factors. To do this, $P$. aeruginosa uses a mechanisms of cell-to-cell communication called quorum sensing (QS). It allows the bacteria to recognize the population density by sensing and measuring the accumulation of specific small signal molecules that members of the community secrete. When the population density is high, the amount of accumulated signals in the environment is accordingly sufficient to activate signaling pathways that alter bacterial gene expression and activate cooperative responses (Rutherford and Bassler, 2012; Schuster et al., 2013; Fazli et al., 2014).

\section{P. aeruginosa OS CONTROL OF VIRULENCE AND BIOFILM FORMATION}

Being equipped with a relatively large genome, $P$. aeruginosa harbors three distinct but subordinated QS systems: two of LuxI/LuxR-type and a third called the Pseudomonas quinolone signal (PQS) system. The two LuxI/LuxR-type systems are
$N$-acylhomoserine lactone (AHL) dependent. In the first, the LuxI homolog LasI produces a freely diffusible $\mathrm{N}$-3-oxo-dodecanoyl-Lhomoserine lactone (3O- $\mathrm{C}_{12}$-HSL) that is detected by the LuxR homolog cytoplasmic receptor LasR (More et al., 1996; Parsek et al., 1999). In the second, the LuxI homolog RhlI synthesizes another AHL, $N$-butyryl-L-homoserine lactone $\left(\mathrm{C}_{4}\right.$-HSL) that binds to the cytoplasmic receptor RhlR (Ochsner etal., 1994; Pearson et al., 1995); LasR and RhlR are cognate transcriptional regulators. Together, the AHL-LuxR complexes of both circuits control the activation of more than 300 genes in the P. aeruginosa genome. Many of these genes code for production of extracellular products that may be considered as virulence factors, because they can damage host tissues and promote infection, and inflammation. These virulence factors include exotoxin A, elastase, proteases, pyocyanin, lectins, and toxins (Gambello and Iglewski, 1991; Toder et al., 1991; Gambello etal., 1993; Schuster et al., 2003). $P$. aeruginosa uses the third $\mathrm{PQS}$ system to control cooperative responses and gene expression of rhamnolipid, a critical biosurfactant in the late stage of biofilm formation (Ochsner et al., 1994; de Kievit, 2009). The signal molecules of this system are bicyclic compounds, 2-alkyl-4(1H)-quinolones (PQS), produced by Pqs$\mathrm{ABCDH}$ and recognized by the receptor PqsR (Deziel et al., 2004; Diggle et al., 2007). Several of PQS can act not only as a QS signals, but also possess antimicrobial, anticancer, or antiallergenic activities. Together with periplasmic components, outer membrane proteins, phospholipids, toxins, lipopolysaccharide (LPS), and DNA, PQS are typically packed into spherical $50-250 \mathrm{~nm}$ membrane vesicles that $P$. aeruginosa secrete and deliver to the environment. In this way, vesicles have a role in communication 
and competion in microbial communities and with host cells (Heeb et al., 2011; Tashiro et al., 2013). In other cases, P. aeruginosa can directly convey its products to other cells using the type VI secretion system. In addition, bacteria possesses an intracellular orphan receptor QscR, a LuxR homolog (Lintz et al., 2011) that can bind to 3O-C 12 -HSL (Oinuma and Greenberg, 2011). This natural target forms dimers with other receptors, i.e., LasR and RhlR, making them inactive and thereby repressing LasRI- and RhlRIdependent genes leading to prevention of aberrant QS responses before the bacteria reach a quorum in a community (Ledgham et al., 2003). Furthermore, the LasR-3O-C 12 -HSL, RhlR-C $4-H S L$, and PQS-PqsR complexes target the regulation of lasI, rhlI, pqsH, and $p q s R$, which creates an autoinducing feed-forward loop and establishes the tightness and subordination between all three QS systems (Seed et al., 1995; Latifi et al., 1996; Deziel et al., 2004; Xiao et al., 2006; Diggle et al., 2007). Thus, with optimal precision $P$. aeruginosa QS system directly or indirectly controls the expression of more than $10 \%$ of genes for multiple virulence factors, secondary metabolites, swarming motility, and biofilm development (Schuster and Greenberg, 2006; Wagner and Iglewski, 2008; Williams and Camara, 2009).

\section{QS-DRIVEN INTER-KINGDOM SIGNALING}

Prokaryotes and eukaryotes have coexisted for many years, during which time they have been exposed to the signals produced and released by the other. The organisms of two kingdoms have also learnt to sense their various molecules including QS signals to influence gene expression and behavior in a process called interkingdom signaling (Pacheco and Sperandio, 2009; Gonzalez and Venturi, 2013).

The QS signal molecule AHL affects mammalian host cells and its signaling pathways; this was shown using both in vivo and in vitro models for immune cells, fibroblasts, and epithelial cells. For the biological activity of AHL, a long acyl chain with more than $10 \mathrm{C}$-atoms, an intact homoserine lactone ring, and oxo- or hydroxyl substitutions are important. AHL triggers and acts through multiple signaling pathways, e.g., calcium mobilization, activation of Rho GTPases, MAPK, and $\mathrm{NF \kappa B}$ that control diverse functions and behaviors in host cells, like cytoskeleton remodeling, chemotaxis, migration, phagocytosis, epithelial barrier function, differentiation, proliferation, apoptosis, and production of immune mediators. This topic has been thoroughly investigated by many research groups during the last decade and extensively reviewed recently (Williams and Camara, 2009; Jarosz et al., 2011; Teplitski et al., 2011).

Many organisms, including bacteria, fungi, plants, and mammalian can disturb and inactivate AHL by enzymes in a way called quorum quenching (Czajkowski and Jafra, 2009; Chen et al., 2013). Humans have also developed an ability to destroy AHL via a class of quorum quenching enzymes called paraoxonases (Amara et al., 2011).

Here, we will further focus on mostly our research on how bacterial QS conversation changes the behavior and function of human neutrophils, macrophages, and epithelial cells, and the signaling responsible for the recognition of AHL.

\section{EPITHELIAL BARRIER INTEGRITY AND 30- $\mathrm{C}_{12}$-HSL}

Epithelial cells are positioned strategically to provide both physical and immune barriers to pathogens and other environmental agents. The physical barrier is created by epithelial cell-to-cell junctions that prevent for instance invasion of pathogens and food constituents. The junctions are multiprotein associations of transmembrane proteins connected to cytoplasmic plaque proteins and the actin cytoskeleton (Van Itallie and Anderson, 2004; Balda and Matter, 2008; Furuse, 2010; Ivanov et al., 2010; Capaldo et al., 2014). In a model of polarized epithelial cells, 3O-C $12^{-}$ HSL alters their barrier integrity (Figure 1), as evidenced by decreased transepithelial electrical resistance and increased paracellular flux of different-sized dextrans (Vikstrom et al., 2006). The cell junction complexes occludin-ZO-1, JAM-ZO-1 and E-cadherin- $\beta$-catenin were disrupted and the expression and distribution of proteins were affected (Vikstrom et al., 2006, 2009, 2010). Some junctional cytoplasmic proteins play a scaffolding role in linking the actin cytoskeleton and helping to recruit an array of signaling pathways, for example the MAPK cascade molecules, protein kinases, and protein phosphatases (Balda and Matter, 2009; Rodgers and Fanning, 2011). Both p38 and p42/44 MAPK are involved in the $3 \mathrm{O}-\mathrm{C}_{12}$-HSL-induced leaky barrier (Vikstrom etal., 2006). Moreover, the disrupted cell junction associations and enhanced paracellular permeability are paralleled by alterations in the phosphorylation status of $\mathrm{TJ}$ and $\mathrm{AJ}$ proteins (Figure 1; Vikstrom et al., 2009, 2010). $\mathrm{Ca}^{2+}$ is another important component in the regulating of immune and physical barriers of the epithelium. Mucosal epithelial cells are as other cells, equipped with $\mathrm{Ca}^{2+}$-dependent signaling which allows them to initiate immune response to bacteria and their products. The participation of $\mathrm{Ca}^{2+}$ as a second messenger is thus vital to many physiological processes of the epithelia including response to bacteria (Vandenbroucke et al., 2008; Varani, 2011). 3O-C 12 -HSL can mobilize intracellular calcium through influx from surrounding and release from thapsigargin-sensitive stores via inositol 1,4,5-triphosphate receptors, $\mathrm{IP}_{3} \mathrm{R}$ (Figure 1; Vikstrom et al., 2010). These receptors are based in the endoplasmatic reticulum (ER) and regulated by their messengers $\mathrm{IP}_{3}$ (Ivanova et al., 2014). Together with ER, the actin cytoskeleton is also critically involved in $\mathrm{Ca}^{2+}$ storage and release as well as in the regulation of store-coupled $\mathrm{Ca}^{2+}$ entry (Lange and Gartzke, 2006).

\section{0- $\mathrm{C}_{12}$-HSL-MEDIATED EPITHELIAL MIGRATION AND WOUND HEALING}

Establishing and contributing to both physical and immune barriers, the epithelial cells also have to be constantly renewed and prepared to move. After injury, caused by for example oxidative stress, inflammation and infection, the epithelium undergo a wound-healing process. This is dependent on the balance of migration, proliferation, and differentiation of the cells within the wound area (Sturm and Dignass, 2008). Restitution of the epithelium requires extensive reorganization of the cytoskeleton and cellular junctions, regulated by the Rho family of small GTPases, like Rho, Rac, and Cdc42 (Kjoller and Hall, 1999; Evers etal., 2000). 3O- $\mathrm{C}_{12}-\mathrm{HSL}$ modulates epithelial cell migration in a dose- and time-dependent manner 


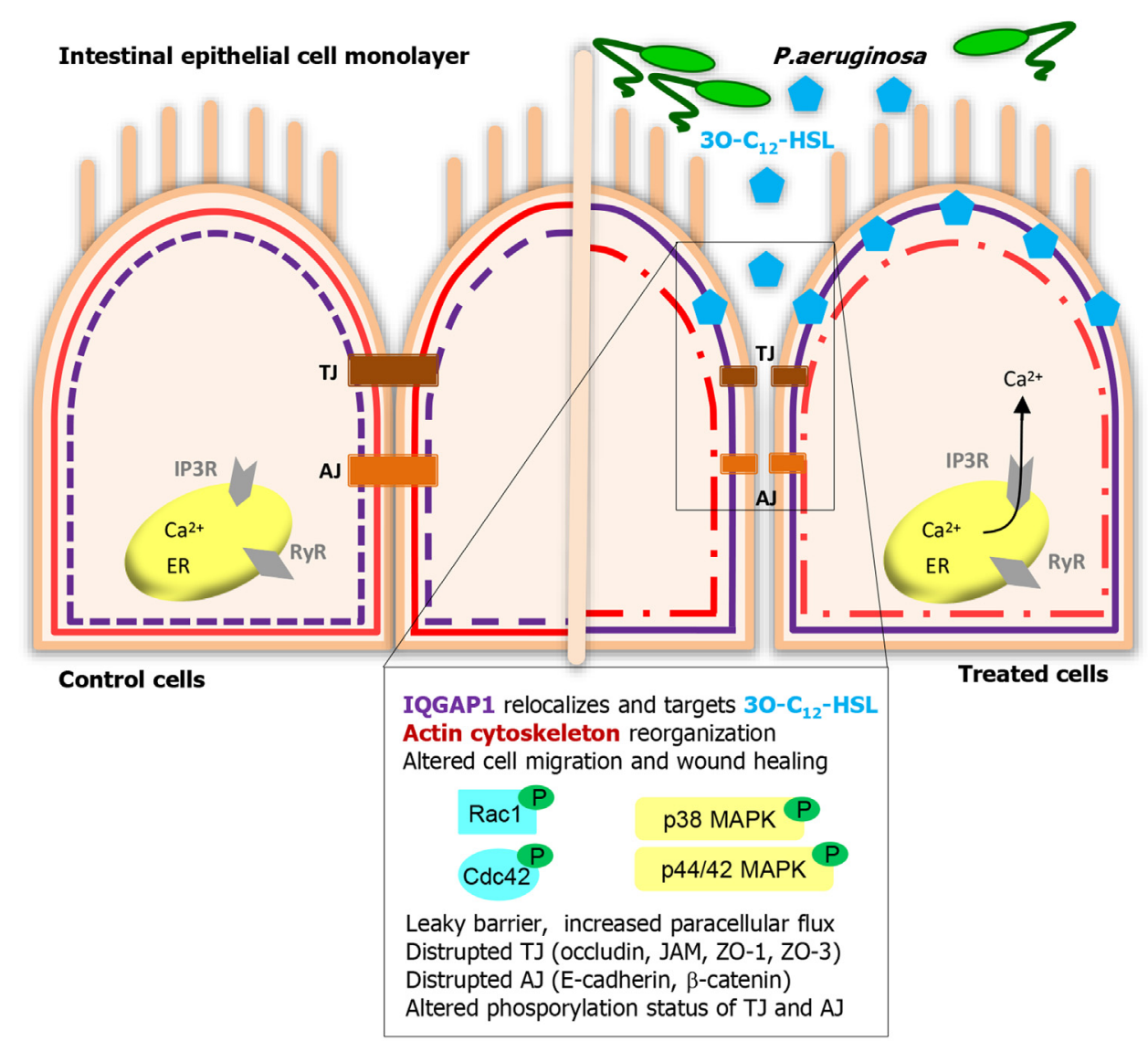

FIGURE 1 | Human intestinal epithelial cells listen to and act on Pseudomonas aeruginosa $\mathbf{3 0}-\mathbf{C}_{\mathbf{1 2}}-\mathbf{H S L}$ signaling. IQGAP1 is a novel membrane-associated target for $30-\mathrm{C}_{12}-\mathrm{HSL}$ that helps human epithelial cell recognize and response to bacterial OS signaling. Further, $30-\mathrm{C}_{12}-\mathrm{HSL}$ triggers multiple signaling pathways, those include calcium mobilization, activation of Rho GTPases Rac1/Cdc42, MAPK, protein kinases, and protein phosphotases. These can control diverse functions and behaviors in epithelial cells, like cytoskeleton remodeling, migration, wound healing, barrier integrity, and paracellular permeability.
(Karlsson et al., 2012b) inducing remodeling of cytoskeletal actin (Vikstrom et al., 2006). The upstream effectors of this, and thereby regulators of cell shape and motility are the previously mentioned Rho family GTPases Rac1 and Cdc42. The Rho GTPases cycle between an active and inactive status by binding GTP and by hydrolysis of GTP to GDP, acting as molecular "onoff" switch (Wennerberg and Der, 2004). The signaling can also be modulated by their phosphorylation state via AKT1 kinase (Kwon et al., 2000). Together with the effect of 3O-C 12 HSL on cell migration, low doses of $3 \mathrm{O}-\mathrm{C}_{12}-\mathrm{HSL}$ over shorter time spans initiated phosphorylation of $\mathrm{Rac1} / \mathrm{Cdc} 42$, whereas high concentrations rapidly decrease the level of phosphorylated Rac/Cdc42 (Karlsson et al., 2012b). Taken together, 3O-C 12 HSL can alter barrier functions and migration in epithelial cells (Figure 1).

The immune barrier of epithelial cells is potentiated through detection of antigens and rapid signaling to recruit phagocytes to the site of infection and tissue damage. They paracellulary transmigrate across the epithelium, and cell junction protein JAM mediate this process as it is also receptor for leukocyte integrins (Zen and Parkos, 2003). Phagocytes, like neutrophils and macrophages, are key players in the innate immune defenses, providing protection from invading bacteria and tissue damage. Bacterial QS conversation may change their behavior and function and the signaling responsible for the sensing of AHL.

\section{AHL AS A STRONG CHEMOATTRACTANT FOR NEUTROPHILS}

Neutrophils are small and rapidly moving phagocytes with a short life span in circulation, always appearing at the early onset of infection. They sense the bacteria very well, which gives them a head start in controlling inflammation, infection, and biofilm formation. Following activation by bacterial products or immune stimuli, they execute specialized functions of chemotaxis, phagocytosis, and generation of reactive oxygen species (ROS). 3oxo- $\mathrm{C}_{12}$-HSL and 3 -oxo- $\mathrm{C}_{10}$-HSL, but not $\mathrm{C}_{4}$-HSL, can act as a strong chemoattractants for human neutrophils and induce their migration to the site of AHL in a dose-dependent manner (Zimmermann et al., 2006; Karlsson et al., 2012a). This put long chain AHL in a position among potent bona fide chemoattractants, such as chemokines, cytokines (IL-8 and GM-CSF), leukotriene $\mathrm{B}_{4}$, platelet activating factor, products from bacteria (formylated peptides and LPS), signals from dying cells (such 
as TNF- $\alpha$ ), although higher molar concentrations of AHL were required (Figure 2A). Chemotaxis and migration towards AHL are paralleled by cytoskeletal $\mathrm{F}$-actin accumulation in the leading edge of neutrophils, by increased F-actin-to-G-actin ratio and via activation of Rho GTPases Rac1 and Cdc42 (Karlsson et al., 2012a). Rac1 regulates the formation of lamellipodia protrusions and membrane ruffles, and Cdc42 triggers filopodial extensions (Kjoller and Hall, 1999; Evers et al., 2000). Two long acyl chain AHL with 10 and 12 C-atoms activated phospholipase $C \gamma 1$ and mobilized intracellular calcium via the $\mathrm{IP}_{3} \mathrm{R}$ at

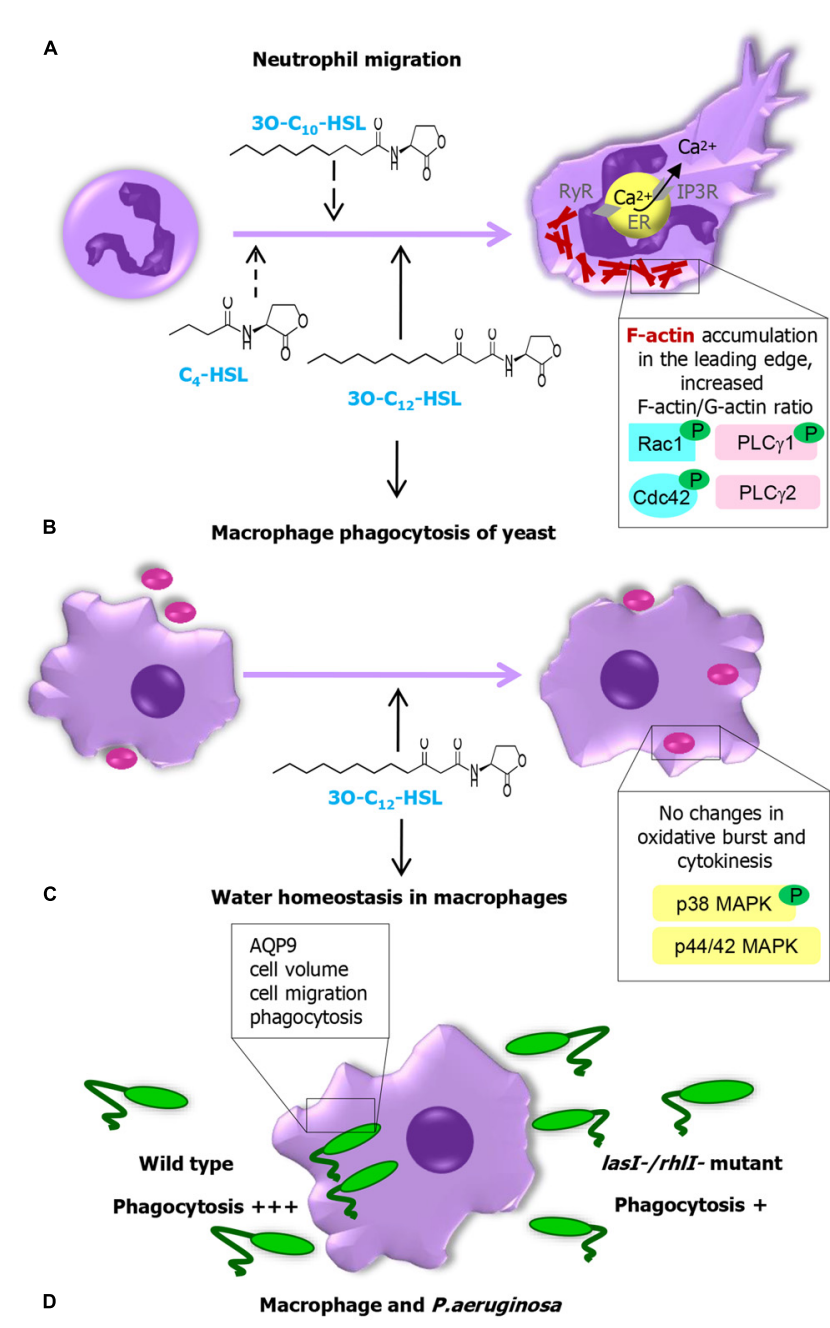

FIGURE 2 | Pseudomonas aeruginosa AHL changes the behavior and function of human innate immune cells and the signaling machinery responsible for the recognition of AHL. (A) Long chain AHLs are strong chemoattractants for neutrophils. Chemotaxis and migration towards these AHLs are paralleled by cytoskeletal F-actin accumulation in the leading edge and increased F-actin-to-G-actin ratio via activation of small GTPases Rac1/Cdc42, phosphorylation of PLC $\gamma 1$ and mobilization of calcium via $I_{3} \mathrm{R}$ at ER. (B) $30-\mathrm{C}_{12}-\mathrm{HSL}$ and macrophage activity. $30-\mathrm{C}_{12}-\mathrm{HSL}$ increases phagocytic capacity of macrophages via the p38, but not p42/44 MAPK, having no influence on their oxidative metabolism, or production of cytokines. (C) $30-\mathrm{C}_{12}$-HSL-mediated water homeostasis in macrophages. (D) Macrophage phagocytosis of $P$. aeruginosa wild type and lasl-/rhllmutant lacking production of $\mathrm{QS}$ molecules $3 \mathrm{O}-\mathrm{C}_{12}-\mathrm{HSL}$ and $\mathrm{C}_{4}-\mathrm{HSL}$. endoplasmic reticulum, whereas an AHL with a short acyl chain failed to do this (Karlsson et al., 2012a; Figure 2A). Thus, recognition of AHL QS signals by neutrophils may play a critical role in their recruitment during infections and early stage of biofilm formation.

\section{AHL AND MACROPHAGE ACTIVITY}

Other important players in the innate immune system are macrophages, cells differentiated from monocytes in tissues and stimulated by neutrophils to come to the site of infection after them. Macrophages harbor the characteristics of innate immune cells and traits that initiate mechanisms of adaptive immunity. In response to microbial antigens, they can display strong phagocytic activity, generation of "killer" anti-microbial ROS, NO, "tissue repair" ornithine, pro-inflammatory cytokines stimulating other immune cells to respond to pathogens. In a macrophage phagocytosis model with Saccharomyces cerevisiae as preys, $3 \mathrm{O}-\mathrm{C}_{12}$-HSL increased phagocytic capacity via the p38, but not the p42/44 MAPK signaling pathway (Figure 2B). It had no influence on macrophages oxidative metabolism, the level of ROS or production of cytokines (Vikstrom et al., 2005). In P. aeruginosa, two functional QS genes, lasI, and rhlI, which are responsible for synthesis of signal molecules $3 \mathrm{O}-\mathrm{C}_{12}$ HSL and $\mathrm{C}_{4}$-HSL strongly contribute to effective macrophage phagocytosis of this pathogen. AQP9 controls cell migration by accumulation in membrane protrusions and domains preceding their expansions (Karlsson etal., 2011, 2013a,b). This trigger actin cytoskeleton to be remodeled and further regulate macrophage shape, migration, and phagocytosis of microorganisms (Figure 2D). 3O- $\mathrm{C}_{12}$-HSL caused a rapid and prolonged cell-volume increase controlled by AQP9 in human macrophages (Figure 2C), which can be a danger signal and protection mechanism (Hoffmann et al., 2009; Compan et al., 2012). AQP9 is involved in Escherichia coli LPS-enhanced brain water content and blood-brain barrier permeability (Wang etal., 2009) and has been identified as a one of markers of chronic inflammation in patients with psoriasis, rheumatoid arthritis, and inflammatory bowel disease (Mesko et al., 2010).

\section{HUMAN CELL TARGETS FOR 30- $\mathrm{C}_{12}$-HSL}

Identifying targets for AHL allows better understanding of QS communication during host-bacteria interactions. The recognition of $3 \mathrm{O}-\mathrm{C}_{12}$-HSL by mammalian cells probably does not rely on pattern-recognition receptors (PRRs) that usually sense invariant microbial motifs (PAMPs, pathogen-associated molecular patterns) present on or shed from bacteria (LPS, lipoteichoic acid, flagellin, and DNA). The canonical class of PRRs, the membrane-bound toll-like receptors (TLRs) located on immune cells, do not interact with 3O-C 12 -HSL (Kravchenko et al., 2006). Still, as for TLR activation, AHL can trigger and act through multiple signaling pathways, which include calcium signaling, activation of Rho GTPases, MAPK, and transcription factor $\mathrm{NF} \kappa \mathrm{B}$ that control expression of pro-inflammatory mediators, cytokines, chemokines, enzymes, and interferones (Smith et al., 2002; Shiner et al., 2006; Kravchenko et al., 2008; Mayer et al., 2011; Karlsson et al., 2012a; Glucksam-Galnoy et al., 2013). These 
mediators are involved in the coordination of innate immune response and recruit effector cells of the adaptive immune system to the site of the infection to combat the invading bacteria.

During the recognition of $3 \mathrm{O}-\mathrm{C}_{12}$-HSL by mammalian cells, this lipophilic molecule with a long acyl chain and an intact homoserine lactone ring may interact directly with phospholipids in model membrane systems and in T-cell membranes (Davis et al., 2010). On entering host cells (Shiner et al., 2004; Ritchie et al., 2007), 3O-C 12 -HSL can utilize intracellular nuclear peroxisome proliferator-activated receptors (PPAR) to affect NF- $\kappa \mathrm{B}$ signaling (Jahoor et al., 2008; Cooley et al., 2010). The binding of 3O-C 12 HSL to nuclear PPAR does not exclude the existence of cell surface or membrane-associated receptors, which after binding to $3 \mathrm{O}$ $\mathrm{C}_{12}$-HSL likely help phosphorylate phospholipase $\mathrm{C}$ and evoke an increase in intracellular calcium (Shiner et al., 2006; Davis et al., 2010; Karlsson et al., 2012a).

Several groups have designed probes and affinity matrixes which could be utilized to detect the mammalian target of 3O$\mathrm{C}_{12}$-HSL (Dubinsky et al., 2009; Garner et al., 2011; Praneenararat etal., 2011; Dubinsky etal., 2013). Using a biotin-based 3O$\mathrm{C}_{12}$-HSL probe, LC-MS/MS, and super-resolution microscopy, the IQ-motif-containing GTPase-activating protein IQGAP1 was identified as a putative human target for $3 \mathrm{O}-\mathrm{C}_{12}-\mathrm{HSL}$ in epithelial cells (Figure 1; Karlsson et al., 2012b). IQGAP1 contains multiple domains for binding other proteins and localizes in the leading edge of migrating cells (Briggs and Sacks, 2003; Noritake et al., 2004; Bensenor et al., 2007). It directly interacts with and stabilizes the Rho-family GTPases, Rac1, and Cdc42 in their GTP-bound state (Swart-Mataraza et al., 2002; Briggs and Sacks, 2003), playing an essential role in cell shape, vesicle trafficking, and directional migration (Bensenor et al., 2007). It likely mediates these processes through its other domains, linking it to actin, myosin, $\beta$-catenin, E-cadherin, calmodulin, and MAPK (Noritake etal., 2005; Brandt and Grosse, 2007), which allows it to function as a true scaffolding protein (Figure 1). The interaction of $3 \mathrm{O}-\mathrm{C}_{12}$-HSL with the cell membrane, diffusion and entering into the cytoplasm, targeting of IQGAP1 and PPAR do not exclude each other. It has, for example been shown that different types of lipids, such as chemoattractant leukotriene $\mathrm{B}_{4}$, can bind to both the cell surface receptor LTB4, and nuclear PPAR.

\section{CONCLUDING REMARKS}

During the last decade of research remarkable insight has been gained into the mechanisms of bacterial QS communication and that $P$. aeruginosa $3 \mathrm{O}-\mathrm{C}_{12}$ - HSL plays at least two distinct roles. Besides regulating bacterial social behavior and offering density-dependent fitness advantages, expression of virulence factors, and biofilm development in bacteria, it also plays a crucial role in the behavior of eukaryotic host cells regulating various vital functions. Moreover, as QS circuits often control virulence and biofilm, there is a high interest in interfering with QS as a new strategy to overcome infectious diseases and biofilm formation (Amara et al., 2011; Heeb etal., 2011; Jakobsen etal., 2013; LaSarre and Federle, 2013).

\section{ACKNOWLEDGMENTS}

We apologize to those colleagues whose work could not be cited owing to space constraints. We thank our colleagues at University of Linköping for joint work, collaborations, insightful discussions and helpful suggestions, and especially Professor Karl-Eric Magnusson, Professor Peter Konradsson, Dr. Lan Bui, Dr. Maria Turkina, Dr. Thommie Karlsson, Dr. Augustas Pivorunas, Ms. Farah Musse, Ms. Olena Yakymenko, Ms. Joanna Gradin, Ms. Susanna Bohman, Mr. Risul Amin, and Ms. Andrea Molinas. We also thank Dr. Hans Blom and Professor Hjalmar Brismar (Advanced Light Microscopy Group, SciLifeLab Stockholm, Sweden). We recognize the help from Cayman Chemical (Ann Arbor, MI, USA) in the design and synthesis of AHL probes according to our suggestions. The work was supported by grants from the Swedish Research Council, the European Science foundation (TraPPs Euromembrane project), Euro-BioImaging Proof-of Concept Studies, the King Gustaf V 80 Year Foundation, Magnus Bergvalls Foundation and the Faculty of Health Sciences, Linköping University.

\section{REFERENCES}

Amara, N., Krom, B. P., Kaufmann, G. F., and Meijler, M. M. (2011). Macromolecular inhibition of quorum sensing: enzymes, antibodies, and beyond. Chem. Rev. 111, 195-208. doi: $10.1021 / \mathrm{cr} 100101 \mathrm{c}$

Balda, M. S., and Matter, K. (2008). Tight junctions at a glance. J. Cell Sci. 121(Pt 22), 3677-3682. doi: 10.1242/jcs.023887

Balda, M. S., and Matter, K. (2009). Tight junctions and the regulation of gene expression. Biochim. Biophys. Acta 1788, 761-767. doi: 10.1016/j.bbamem.2008.11.024

Bensenor, L. B., Kan, H. M., Wang, N., Wallrabe, H., Davidson, L. A., Cai, Y., et al. (2007). IQGAP1 regulates cell motility by linking growth factor signaling to actin assembly. J. Cell Sci. 120(Pt 4), 658-669. doi: 10.1242/jcs.03376

Brandt, D. T., and Grosse, R. (2007). Get to grips: steering local actin dynamics with IQGAPs. EMBO Rep. 8, 1019-1023. doi: 10.1038/sj.embor.7401089

Briggs, M. W., and Sacks, D. B. (2003). IQGAP1 as signal integrator: $\mathrm{Ca}^{2+}$, calmodulin, Cdc42 and the cytoskeleton. FEBS Lett. 542, 7-11. doi: 10.1016/S00145793(03)00333-8

Capaldo, C. T., Farkas, A. E., and Nusrat, A. (2014). Epithelial adhesive junctions. F1000Prime Rep. 6:1. doi: 10.12703/P6-1

Chen, F., Gao, Y., Chen, X., Yu, Z., and Li, X. (2013). Quorum quenching enzymes and their application in degrading signal molecules to block quorum sensing-dependent infection. Int. J. Mol. Sci. 14, 17477-17500. doi: 10.3390/ijms140917477

Compan, V., Baroja-Mazo, A., Lopez-Castejon, G., Gomez, A. I., Martinez, C. M., Angosto, D., et al. (2012). Cell volume regulation modulates NLRP3 inflammasome activation. Immunity 37, 487-500. doi: 10.1016/j.immuni.2012. 06.013

Cooley, M. A., Whittall, C., and Rolph, M. S. (2010). Pseudomonas signal molecule 3-oxo-C12-homoserine lactone interferes with binding of rosiglitazone to human PPARgamma. Microbes Infect. 12, 231-237. doi: 10.1016/j.micinf.2009.12.009

Czajkowski, R., and Jafra, S. (2009). Quenching of acyl-homoserine lactonedependent quorum sensing by enzymatic disruption of signal molecules. Acta Biochim. Pol. 56, 1-16.

Davis, B., Jensen, M. R., Williams, P., and O'Shea, P. (2010). The interaction of $\mathrm{N}$-acylhomoserine lactone quorum sensing signaling molecules with biological membranes: implications for inter-kingdom signaling. PLoS ONE 5:e13522. doi: 10.1371/journal.pone.0013522

de Kievit, T. R. (2009). Quorum sensing in Pseudomonas aeruginosa biofilms. Environ. Microbiol. 11, 279-288. doi: 10.1111/j.1462-2920.2008.01792.x

Deziel, E., Lepine, F., Milot, S., He, J., Mindrinos, M. N., Tompkins, R. G., et al. (2004). Analysis of Pseudomonas aeruginosa 4-hydroxy-2-alkylquinolines (HAQs) reveals a role for 4-hydroxy-2-heptylquinoline in cell-to-cell communication. Proc. Natl. Acad. Sci. U.S.A. 101, 1339-1344. doi: 10.1073/pnas.0307 694100 
Diggle, S. P., Matthijs, S., Wright, V. J., Fletcher, M. P., Chhabra, S. R., Lamont, I. L., et al. (2007). The Pseudomonas aeruginosa 4-quinolone signal molecules HHQ and PQS play multifunctional roles in quorum sensing and iron entrapment. Chem. Biol. 14, 87-96. doi: 10.1016/j.chembiol.2006.11.014

Dubinsky, L., Delago, A., Amara, N., Krief, P., Rayo, J., Zor, T., et al. (2013). Species selective diazirine positioning in tag-free photoactive quorum sensing probes. Chem. Commun. (Camb.) 49, 5826-5828. doi: 10.1039/c3cc43092h

Dubinsky, L., Jarosz, L. M., Amara, N., Krief, P., Kravchenko, V. V., Krom, B. P., et al. (2009). Synthesis and validation of a probe to identify quorum sensing receptors. Chem. Commun. (Camb.) 47, 7378-7380. doi: 10.1039/b917507e

Evers, E. E., Zondag, G. C., Malliri, A., Price, L. S., ten Klooster, J. P., van der Kammen, R. A., et al. (2000). Rho family proteins in cell adhesion and cell migration. Eur. J. Cancer 36, 1269-1274. doi: 10.1016/S0959-8049(00)00091-5

Fazli, M., Almblad, H., Rybtke, M. L., Givskov, M., Eberl, L., and Tolker-Nielsen, T. (2014). Regulation of biofilm formation in Pseudomonas and Burkholderia species. Environ. Microbiol. doi: 10.1111/1462-2920.12448 [Epub ahead of print].

Furuse, M. (2010). Molecular basis of the core structure of tight junctions. Cold Spring Harb. Perspect. Biol. 2:a002907. doi: 10.1101/cshperspect.a002907

Gambello, M. J., and Iglewski, B. H. (1991). Cloning and characterization of the Pseudomonas aeruginosa lasR gene, a transcriptional activator of elastase expression. J. Bacteriol. 173, 3000-3009.

Gambello, M. J., Kaye, S., and Iglewski, B. H. (1993). LasR of Pseudomonas aeruginosa is a transcriptional activator of the alkaline protease gene (apr) and an enhancer of exotoxin A expression. Infect. Immun. 61, 1180-1184.

Garner, A. L., Yu, J., Struss, A. K., Lowery, C. A., Zhu, J., Kim, S. K., et al. (2011). Synthesis of 'clickable' acylhomoserine lactone quorum sensing probes: unanticipated effects on mammalian cell activation. Bioorg. Med. Chem. Lett. 21, 2702-2705. doi: 10.1016/j.bmcl.2010.11.122

Glucksam-Galnoy, Y., Sananes, R., Silberstein, N., Krief, P., Kravchenko, V. V., Meijler, M. M., et al. (2013). The bacterial quorum-sensing signal molecule N3-oxo-dodecanoyl-L-homoserine lactone reciprocally modulates pro- and antiinflammatory cytokines in activated macrophages. J. Immunol. 191, 337-344. doi: 10.4049/jimmunol.1300368

Gonzalez, J. F., and Venturi, V. (2013). A novel widespread interkingdom signaling circuit. Trends Plant Sci. 18, 167-174. doi: 10.1016/j.tplants.2012.09.007

Heeb, S., Fletcher, M. P., Chhabra, S. R., Diggle, S. P., Williams, P., and Camara, M. (2011). Quinolones: from antibiotics to autoinducers. FEMS Microbiol. Rev. 35, 247-274. doi: 10.1111/j.1574-6976.2010.00247.x

Hoffmann, E. K., Lambert, I. H., and Pedersen, S. F. (2009). Physiology of cell volume regulation in vertebrates. Physiol. Rev. 89, 193-277. doi: 10.1152/physrev.00037.2007

Ivanov, A. I., Parkos, C. A., and Nusrat, A. (2010). Cytoskeletal regulation of epithelial barrier function during inflammation. Am. J. Pathol. 177, 512-524. doi: 10.2353/ajpath.2010.100168

Ivanova, H., Vervliet, T., Missiaen, L., Parys, J. B., De Smedt, H., and Bultynck, G. (2014). Inositol 1,4,5-trisphosphate receptor-isoform diversity in cell death and survival. Biochim. Biophys. Acta doi: 10.1016/j.bbamcr.2014.03.007 [Epub ahead of print]

Jahoor, A., Patel, R., Bryan, A., Do, C., Krier, J., Watters, C., et al. (2008). Peroxisome proliferator-activated receptors mediate host cell proinflammatory responses to Pseudomonas aeruginosa autoinducer. J. Bacteriol. 190, 4408-4415. doi: 10.1128/JB.01444-07

Jakobsen, T. H., Bjarnsholt, T., Jensen, P. O., Givskov, M., and Hoiby, N. (2013). Targeting quorum sensing in Pseudomonas aeruginosa biofilms: current and emerging inhibitors. Future Microbiol. 8, 901-921. doi: 10.2217/fmb.13.57

Jarosz, L. M., Ovchinnikova, E. S., Meijler, M. M., and Krom, B. P. (2011). Microbial spy games and host response: roles of a Pseudomonas aeruginosa small molecule in communication with other species. PLoS Pathog. 7:e1002312. doi: 10.1371/journal.ppat.1002312

Karlsson, T., Bolshakova, A., Magalhaes, M. A., Loitto, V. M., and Magnusson, K. E. (2013a). Fluxes of water through aquaporin 9 weaken membranecytoskeleton anchorage and promote formation of membrane protrusions. PLoS ONE 8:e59901. doi: 10.1371/journal.pone.0059901

Karlsson, T., Lagerholm, B. C., Vikstrom, E., Loitto, V. M., and Magnusson, K. E. (2013b). Water fluxes through aquaporin-9 prime epithelial cells for rapid wound healing. Biochem. Biophys. Res. Commun. 430, 993-998. doi: 10.1016/j.bbrc.2012.11.125
Karlsson, T., Glogauer, M., Ellen, R. P., Loitto, V. M., Magnusson, K. E., and Magalhaes, M. A. (2011). Aquaporin 9 phosphorylation mediates membrane localization and neutrophil polarization. J. Leukoc. Biol. 90, 963-973. doi: 10.1189/jlb.0910540

Karlsson, T., Musse, F., Magnusson, K. E., and Vikstrom, E. (2012a). NAcylhomoserine lactones are potent neutrophil chemoattractants that act via calcium mobilization and actin remodeling. J. Leukoc. Biol. 91, 15-26. doi: 10.1189/jlb.0111034

Karlsson, T., Turkina, M. V., Yakymenko, O., Magnusson, K. E., and Vikstrom, E. (2012b). The Pseudomonas aeruginosa $\mathrm{N}$-acylhomoserine lactone quorum sensing molecules target IQGAP1 and modulate epithelial cell migration. PLoS Pathog. 8:e1002953. doi: 10.1371/journal.ppat.1002953

Kjoller, L., and Hall, A. (1999). Signaling to Rho GTPases. Exp. Cell Res. 253, 166-179. doi: 10.1006/excr.1999.4674

Kravchenko, V. V., Kaufmann, G. F., Mathison, J. C., Scott, D. A., Katz, A. Z., Grauer, D. C., et al. (2008). Modulation of gene expression via disruption of NF-kappaB signaling by a bacterial small molecule. Science 321, 259-263. doi: $10.1126 /$ science.1156499

Kravchenko, V. V., Kaufmann, G. F., Mathison, J. C., Scott, D. A., Katz, A. Z., Wood, M. R., et al. (2006). N-(3-oxo-acyl)homoserine lactones signal cell activation through a mechanism distinct from the canonical pathogen-associated molecular pattern recognition receptor pathways. J. Biol. Chem. 281, 28822-28830. doi: 10.1074/jbc.M606613200

Kwon, T., Kwon, D. Y., Chun, J., Kim, J. H., and Kang, S. S. (2000). Akt protein kinase inhibits Rac1-GTP binding through phosphorylation at serine 71 of Racl. J. Biol. Chem. 275, 423-428. doi: 10.1074/jbc.275.1.423

Lange, K., and Gartzke, J. (2006). F-actin-based Ca signaling-a critical comparison with the current concept of Ca signaling. J. Cell. Physiol. 209, 270-287. doi: 10.1002/jcp. 20717

LaSarre, B., and Federle, M. J. (2013). Exploiting quorum sensing to confuse bacterial pathogens. Microbiol. Mol. Biol. Rev. 77, 73-111. doi: 10.1128/MMBR.00046-12

Latifi, A., Foglino, M., Tanaka, K., Williams, P., and Lazdunski, A. (1996). A hierarchical quorum-sensing cascade in Pseudomonas aeruginosa links the transcriptional activators LasR and RhIR (VsmR) to expression of the stationaryphase sigma factor RpoS. Mol. Microbiol. 21, 1137-1146. doi: 10.1046/j.13652958.1996.00063.x

Ledgham, F., Ventre, I., Soscia, C., Foglino, M., Sturgis, J. N., and Lazdunski, A. (2003). Interactions of the quorum sensing regulator QscR: interaction with itself and the other regulators of Pseudomonas aeruginosa LasR and RhlR. Mol. Microbiol. 48, 199-210. doi: 10.1046/j.1365-2958.2003.03423.x

Lintz, M. J., Oinuma, K., Wysoczynski, C. L., Greenberg, E. P., and Churchill, M. E. (2011). Crystal structure of QscR, a Pseudomonas aeruginosa quorum sensing signal receptor. Proc. Natl. Acad. Sci. U.S.A. 108, 15763-15768. doi: 10.1073/pnas.1112398108

Mayer, M. L., Sheridan, J. A., Blohmke, C. J., Turvey, S. E., and Hancock, R. E. (2011). The Pseudomonas aeruginosa autoinducer 3O-C12 homoserine lactone provokes hyperinflammatory responses from cystic fibrosis airway epithelial cells. PLoS ONE 6:e16246. doi: 10.1371/journal.pone.0016246

Mesko, B., Poliska, S., Szegedi, A., Szekanecz, Z., Palatka, K., Papp, M., et al. (2010). Peripheral blood gene expression patterns discriminate among chronic inflammatory diseases and healthy controls and identify novel targets. BMC Med. Genomics 3:15. doi: 10.1186/1755-8794-3-15

More, M. I., Finger, L. D., Stryker, J. L., Fuqua, C., Eberhard, A., and Winans, S. C. (1996). Enzymatic synthesis of a quorum-sensing autoinducer through use of defined substrates. Science 272, 1655-1658. doi: 10.1126/science.272.5268.1655

Noritake, J., Fukata, M., Sato, K., Nakagawa, M., Watanabe, T., Izumi, N., et al. (2004). Positive role of IQGAP1, an effector of Rac1, in actin-meshwork formation at sites of cell-cell contact. Mol. Biol. Cell 15, 1065-1076. doi: 10.1091/mbc.E03-08-0582

Noritake, J., Watanabe, T., Sato, K., Wang, S., and Kaibuchi, K. (2005). IQGAP1: a key regulator of adhesion and migration. J. Cell Sci. 118(Pt 10), 2085-2092. doi: $10.1242 /$ jcs. 02379

Ochsner, U. A., Koch, A. K., Fiechter, A., and Reiser, J. (1994). Isolation and characterization of a regulatory gene affecting rhamnolipid biosurfactant synthesis in Pseudomonas aeruginosa. J. Bacteriol. 176, 2044-2054.

Oinuma, K., and Greenberg, E. P. (2011). Acyl-homoserine lactone binding to and stability of the orphan Pseudomonas aeruginosa quorum-sensing signal receptor QscR. J. Bacteriol. 193, 421-428. doi: 10.1128/JB.01041-10 
Pacheco, A. R., and Sperandio, V. (2009). Inter-kingdom signaling: chemical language between bacteria and host. Curr. Opin. Microbiol. 12, 192-198. doi: 10.1016/j.mib.2009.01.006

Parsek, M. R., Val, D. L., Hanzelka, B. L., Cronan, J. E. Jr., and Greenberg, E. P. (1999). Acyl homoserine-lactone quorum-sensing signal generation. Proc. Natl. Acad. Sci. U.S.A. 96, 4360-4365. doi: 10.1073/pnas.96.8.4360

Pearson, J. P., Passador, L., Iglewski, B. H., and Greenberg, E. P. (1995). A second Nacylhomoserine lactone signal produced by Pseudomonas aeruginosa. Proc. Natl. Acad. Sci. U.S.A. 92, 1490-1494. doi: 10.1073/pnas.92.5.1490

Praneenararat, T., Beary, T. M., Breitbach, A. S., and Blackwell, H. E. (2011). Synthesis and application of an $\mathrm{N}$-acylated l-homoserine lactone derivatized affinity matrix for the isolation of quorum sensing signal receptors. Bioorg. Med. Chem. Lett. 21, 5054-5057. doi: 10.1016/j.bmcl.2011.04.062

Ritchie, A. J., Whittall, C., Lazenby, J. J., Chhabra, S. R., Pritchard, D. I., and Cooley, M. A. (2007). The immunomodulatory Pseudomonas aeruginosa signalling molecule $\mathrm{N}$-(3-oxododecanoyl)-L-homoserine lactone enters mammalian cells in an unregulated fashion. Immunol. Cell Biol. 85, 596-602. doi 10.1038/sj.icb.7100090

Rodgers, L. S., and Fanning, A. S. (2011). Regulation of epithelial permeability by the actin cytoskeleton. Cytoskeleton (Hoboken) 68, 653-660. doi: 10.1002/cm.20547

Rutherford, S. T., and Bassler, B. L. (2012). Bacterial quorum sensing: its role in virulence and possibilities for its control. Cold Spring Harb. Perspect. Med. 2:a012427. doi: 10.1101/cshperspect.a012427

Schuster, M., and Greenberg, E. P. (2006). A network of networks: quorum-sensing gene regulation in Pseudomonas aeruginosa. Int. J. Med. Microbiol. 296, 73-81. doi: 10.1016/j.ijmm.2006.01.036

Schuster, M., Lostroh, C. P., Ogi, T., and Greenberg, E. P. (2003). Identification, timing, and signal specificity of Pseudomonas aeruginosa quorumcontrolled genes: a transcriptome analysis. J. Bacteriol. 185, 2066-2079. doi: 10.1128/JB.185.7.2066-2079.2003

Schuster, M., Sexton, D. J., Diggle, S. P., and Greenberg, E. P. (2013). Acylhomoserine lactone quorum sensing: from evolution to application. Annu. Rev. Microbiol. 67, 43-63. doi: 10.1146/annurev-micro-092412-155635

Seed, P. C., Passador, L., and Iglewski, B. H. (1995). Activation of the Pseudomonas aeruginosa lasI gene by LasR and the Pseudomonas autoinducer PAI an autoinduction regulatory hierarchy. J. Bacteriol. 177, 654-659.

Shiner, E. K., Reddy, S., Timmons, C., Li, G., Williams, S. C., and Rumbaugh, K. P. (2004). Construction of a bacterial autoinducer detection system in mammalian cells. Biol. Proced. Online 6, 268-276. doi: 10.1251/bpo98

Shiner, E. K., Terentyev, D., Bryan, A., Sennoune, S., Martinez-Zaguilan, R., Li, G., et al. (2006). Pseudomonas aeruginosa autoinducer modulates host cell responses through calcium signalling. Cell Microbiol. 8, 1601-1610. doi: 10.1111/j.14625822.2006.00734.x

Smith, R. S., Kelly, R., Iglewski, B. H., and Phipps, R. P. (2002). The Pseudomona autoinducer $\mathrm{N}$-(3-oxododecanoyl) homoserine lactone induces cyclooxygenase2 and prostaglandin E2 production in human lung fibroblasts: implications for inflammation. J. Immunol. 169, 2636-2642. doi: 10.4049/jimmunol.169.5.2636

Sturm, A., and Dignass, A. U. (2008). Epithelial restitution and wound healing in inflammatory bowel disease. World J. Gastroenterol. 14, 348-353. doi: 10.3748/wjg. 14.348

Swart-Mataraza, J. M., Li, Z., and Sacks, D. B. (2002). IQGAP1 is a component of Cdc42 signaling to the cytoskeleton. J. Biol. Chem. 277, 24753-24763. doi: 10.1074/jbc.M111165200

Tashiro, Y., Yawata, Y., Toyofuku, M., Uchiyama, H., and Nomura, N. (2013). Interspecies interaction between Pseudomonas aeruginosa and other microorganisms. Microbes Environ. 28, 13-24. doi: 10.1264/jsme2.ME12167

Teplitski, M., Mathesius, U., and Rumbaugh, K. P. (2011). Perception and degradation of $\mathrm{N}$-acyl homoserine lactone quorum sensing signals by mammalian and plant cells. Chem. Rev. 111, 100-116. doi: 10.1021/cr100045m

Toder, D. S., Gambello, M. J., and Iglewski, B. H. (1991). Pseudomonas aeruginosa LasA: a second elastase under the transcriptional control of lasR. Mol. Microbiol. 5, 2003-2010. doi: 10.1111/j.1365-2958.1991.tb00822.x
Van Itallie, C. M., and Anderson, J. M. (2004). The molecular physiology of tight junction pores. Physiology (Bethesda) 19, 331-338. doi: 10.1152/physiol.00027.2004

Vandenbroucke, E., Mehta, D., Minshall, R., and Malik, A. B. (2008). Regulation of endothelial junctional permeability. Ann. N. Y. Acad. Sci. 1123, 134-145. doi: 10.1196/annals.1420.016

Varani, J. (2011). Calcium, calcium-sensing receptor and growth control in the colonic mucosa. Histol. Histopathol. 26, 769-779.

Vikstrom, E., Bui, L., Konradsson, P., and Magnusson, K. E. (2009). The junctional integrity of epithelial cells is modulated by Pseudomonas aeruginosa quorum sensing molecule through phosphorylation-dependent mechanisms. Exp. Cell Res. 315, 313-326. doi: 10.1016/j.yexcr.2008.10.044

Vikstrom, E., Bui, L., Konradsson, P., and Magnusson, K. E. (2010). Role of calcium signalling and phosphorylations in disruption of the epithelial junctions by Pseudomonas aeruginosa quorum sensing molecule. Eur. J. Cell Biol. 89, 584-597. doi: 10.1016/j.ejcb.2010.03.002

Vikstrom, E., Magnusson, K. E., and Pivoriunas, A. (2005). The Pseudomonas aeruginosa quorum-sensing molecule $\mathrm{N}$-(3-oxododecanoyl)-L-homoserine lactone stimulates phagocytic activity in human macrophages through the p38 MAPK pathway. Microbes Infect. 7, 1512-1518. doi: 10.1016/j.micinf.2005.05.012

Vikstrom, E., Tafazoli, F., and Magnusson, K. E. (2006). Pseudomonas aeruginosa quorum sensing molecule N-(3 oxododecanoyl)-l-homoserine lactone disrupts epithelial barrier integrity of Caco-2 cells. FEBS Lett. 580, 6921-6928. doi: 10.1016/j.febslet.2006.11.057

Wagner, V. E., and Iglewski, B. H. (2008). P. aeruginosa Biofilms in CF Infection. Clin. Rev. Allergy Immunol. 35, 124-134. doi: 10.1007/s12016-008-8079-9

Wang, H., Jin, R., Tian, P., and Zhuo, Z. (2009). Enhanced expression of aquaporin-9 in rat brain edema induced by bacterial lipopolysaccharides. J. Huazhong Univ. Sci. Technolog. Med. Sci. 29, 150-155. doi: 10.1007/s11596-009-0203-4

Wennerberg, K., and Der, C. J. (2004). Rho-family GTPases: it's not only Rac and Rho (and I like it). J. Cell Sci. 117(Pt 8), 1301-1312. doi: 10.1242/jcs.01118

Williams, P., and Camara, M. (2009). Quorum sensing and environmental adaptation in Pseudomonas aeruginosa: a tale of regulatory networks and multifunctional signal molecules. Curr. Opin. Microbiol. 12, 182-191. doi: 10.1016/j.mib.2009.01.005

Xiao, G., He, J., and Rahme, L. G. (2006). Mutation analysis of the Pseudomonas aeruginosa mvfR and pqsABCDE gene promoters demonstrates complex quorum-sensing circuitry. Microbiology 152(Pt 6), 1679-1686. doi: 10.1099/mic.0.28605-0

Zen, K., and Parkos, C. A. (2003). Leukocyte-epithelial interactions. Curr. Opin. Cell Biol. 15, 557-564. doi: 10.1016/S0955-0674(03)00103-0

Zimmermann, S., Wagner, C., Muller, W., Brenner-Weiss, G., Hug, F., Prior, B., et al. (2006). Induction of neutrophil chemotaxis by the quorum-sensing molecule N-(3-oxododecanoyl)-L-homoserine lactone. Infect. Immun. 74, 5687-5692. doi: 10.1128/IAI.01940-05

Conflict of Interest Statement: The authors are not aware of any affiliations, memberships, patents, copyrights, funding, payment, service or other activities or relationships that might be perceived as an affecting the objectivity of this review.

Received: 30 April 2014; accepted: 10 June 2014; published online: 26 June 2014. Citation: Holm A and Vikström E (2014) Quorum sensing communication between bacteria and human cells: signals, targets, and functions. Front. Plant Sci. 5:309. doi: $10.3389 / \mathrm{fpls} .2014 .00309$

This article was submitted to Plant-Microbe Interaction, a section of the journal Frontiers in Plant Science.

Copyright (C) 2014 Holm and Vikström. This is an open-access article distributed under the terms of the Creative Commons Attribution License (CC BY). The use, distribution or reproduction in other forums is permitted, provided the original author(s) or licensor are credited and that the original publication in this journal is cited, in accordance with accepted academic practice. No use, distribution or reproduction is permitted which does not comply with these terms. 